
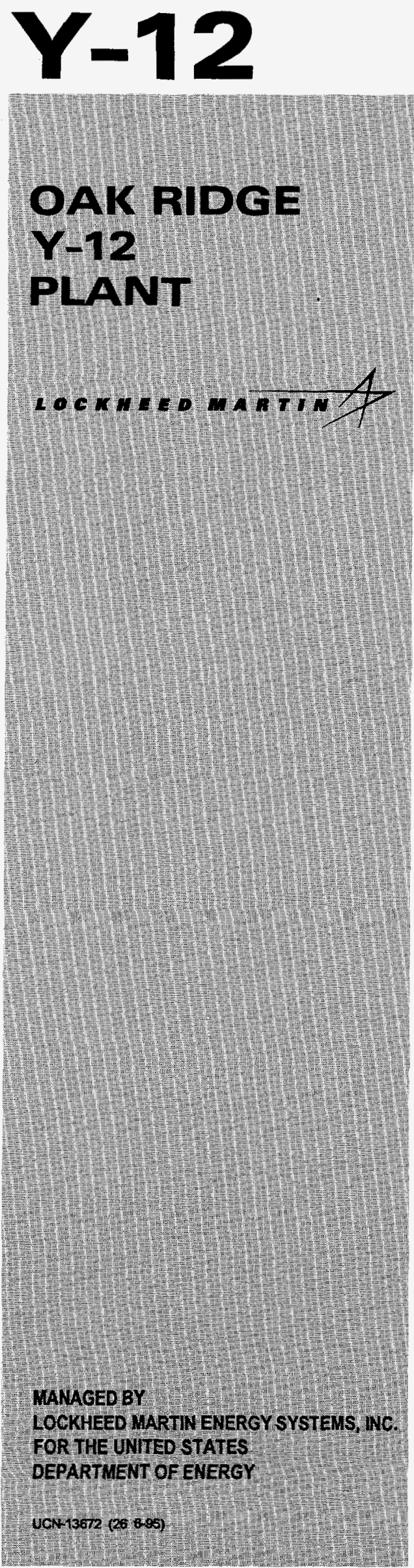

RECEVED

JUL 221997

YIAMT-423
Project Accomplishment Summary for

Project Number 93-Y12P-075-C1

\title{
SEMICONDUCTOR YIELD IMPROVEMENTS THROUGH AUTOMATIC DEFECT CLASSIFICATION
}

Shaun Gleason

Lockheed Martin Energy Systems, Inc.

Ashok Kulkarni

KLA Instruments Corporation

September 30, 1995

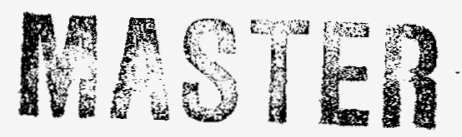

Approved for Public Release;

distribution is unlimited.

\author{
Prepared by the \\ Oak Ridge Y-12 Plant \\ managed by
}

LOCKHEED MARTIN ENERGY SYSTEMS, INC.

for the

U.S. DEPARTMENT OF ENERGY under contract DE-AC05-84OR21400

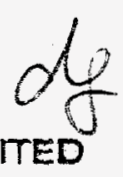




\section{DISCLAIMER}

This report was prepared as an account of work sponsored by an agency of the United States Government. Neither the United States Government nor any agency thereof, nor any of their employees, makes any warranty, express or implied, or assumes any legal liability or responsibility for the accuracy, completeness, or usefulness of any information, apparatus, product, or process disclosed, or represents that its use would not infringe privately owned rights. Reference herein to any specific commercial product, process, or service by trade name, trademark, manufacturer, or otherwise, does not necessarily constitute or imply its endorsement, recommendation, or favoring by the United States Government or any agency thereof. The views and opinions of authors expressed herein do not necessarily state or reflect those of the United States Government or any agency thereof. 


\section{PROJECT ACCOMPLISHMENT SUMMARY}

Title:

Semiconductor Yield Improvements Through Automatic Defẹct Classification

DOE TTI Number: 93-Y12P-075-C1

CRADA Number: ORNL92-0140

Partner: $\quad$ KLA Instruments Corporation

BACKGROUND

Automatic detection of defects during the fabrication of semiconductor wafers is largely automated, but the classification of those defects is still performed manually by technicians. Projections by semiconductor manufacturers predict that with larger wafer sizes and smaller line width technology the number of defects to be manually classified will increase exponentially. This cooperative research and development agreement (CRADA) between Martin Marietta Energy Systems (MMES) and KLA Instruments developed concepts, algorithms and systems to automate the classification of wafer defects to decrease inspection time, improve the reliability of defect classification, and hence increase process throughput and yield. Image analysis, feature extraction, pattern recognition and classification schemes were developed that are now being used as research tools for future products and are being integrated into the KLA line of wafer inspection hardware. An automatic defect classification software research tool was developed and delivered to the CRADA partner to facilitate continuation of this research beyond the end of the partnership.

\section{DESCRIPTION}

KLA Instruments was to generate sets of characterized image pairs with available database information using the KLA 2100 Series Wafer Defect Inspector. These image pairscontained a reasonable distribution of circuit cell backgrounds, normal process variations, flaw types and categories for use by the MMES Staff in developing and testing inspection approaches. KLA and MMES would interactwith the major manufacturers of semiconductor products and key players in the DOE DO microelectronic R\&D program to identify relevant image descriptors and a classification "language" for use with the automated classifier. MMES would develop novel techniques for image segmentation and feature extraction in the presence of semi-regular background texture, and develop feature extraction in the presence of semi-regular background texture, and develop feature vectors that best differentiate between flaw types and classes. MMES would develop high-speed adaptable classifiers based on image feature vectors. Merge classification language, description data-base, and image features into a coherent adaptive classification technique. KLA would identify the hardware, software, and operating procedure modifications required of KLA Instruments' three primary product lines in wafer inspection to accommodate automated defect classification. Perform technical trade-off studies, market assessments, and cost-benefit analysis on the implementations which hold the most promise for benefiting the semiconductor wafer manufacturing industry. MMES would assimilate a developed approach (optimum feature vectors, classification scheme, and classification language) into a demonstration prototype. Complete system testing, verification, performance characterization, system demonstration, and final report. 


\section{DISCLAMIER}

Portions of this document may be illegible in electronic image products. Images are produced from the best available original document. 


\section{BENEFITS TO DOE}

The DOE relies heavily on the availability of high quality, thoroughly tested integrated circuits for practically all Defense Programs ranging from nuclear weapons production, testing, and detonation, to safeguards and security, and advanced manufacturing feedback and control systems. Most of these circuits are purchased commercially and thus the benefit of providing high speed silicon wafer inspection systems to the manufacturers of semiconductor products is inherent.

DOE also develops and produces custom integrated circuits for its program. The Microelectronics Development Laboratory (MDL) at Sandia National Laboratory is responsible for semiconductor manufacturing process development and specific integrated circuit design for many DOE defense and intelligence needs. They have primary responsibility for the Development of high temperature tolerant circuits and radiation hardened circuits and processes. Although the state of the art for these technology areas lag those of the commercial sector in wafer area and line widths, they have already exceeded circuit complexity for which human inspection is viable.

While MDL could benefit directly from the use of an enhanced wafer inspection system, they are basically a low volume, prototype development and demonstration facility. The main economic advantage to DOE-DP with respect to custom integrated circuits lies in receiving high yield manufacturing runs from commercial vendors who mass produce MDL perfected circuits (such as the United Technologies Inc. Microelectronics Center, Colorado Springs, Colorado). Another DP program which could benefit directly from this projects is the joint SEMATECH/DOE Center for Contamination Free Manufacturing also at Sandia National Laboratory. In each of these cases control of the fabrication line to minimize defects and maintain acceptable yields of high quality product is not possible without on-line wafer inspection and defect classification. This project will allow Wafer Inspection Systems to meet current and future demand for yield optimization by providing rapid analysis of the semiconductor manufacturing process.

\section{ECONOMIC BENEFIT}

Defect detection and classification plays an important part in maintaining and improving production yield in semiconductor fabrication lines. A wafer must be processed to 80 or $90 \%$ completion before it can be tested electrically. Optical methods and Scanning Electron Microscopes (SEMs) are the only methods available for inspection during most of the processing.

Because "killer" defects are detected on sample wafers after a lot (usually 25) of wafers has been processed, prompt detection and classification of any defects is essential to correcting process problems and maintaining the yield of the fabrication line. With smaller and smaller design rules (feature size, line width, etc.) The allowable particle and defect sizes are correspondingly reduced. In other words, the range of particle and defect sizes is increased leading to a drastic increase in the number to detect and classify. To this is added the larger wafer size, so the area to be inspected is almost $80 \%$ greater with the new $200-\mathrm{mm}$ diameter wafers than with the older $150-\mathrm{mm}$ wafers. The trend towards a $300-\mathrm{mm}$ diameter wafer standard will again more than double the area to be inspected, hence double the number of defects to detect and classify. 
To put this into a national perspective, the cost of Motorola's newest 200-mm fabrication line in Austin was approximately $\$ 500 \mathrm{M}$. The value of product wafers in a typical process line at any one time is in the range of $\$ 50 \mathrm{M}$ to $\$ 100 \mathrm{M}$. (It normally takes about 6 weeks to completely process a lot of wafers). It should be clear that increasing inspection and analysis time to accommodate the larger wafers and increased number of defect classes cannot be easily tolerated. Both the increased speed of wafer scanning and automation of defect classification is essential for the industry to maintain the volume of production with adequate yield to pay for the rapidly escalating cost of the production facilities and equipment. Improved defect inspection is essential for the long term profitability of U.S. semiconductor industry. A $0.1 \%$ yield improvement in wafer production is worth $\$ 100 \mathrm{M}$ annually to the U.S. semiconductor industry.

\section{PROJECT STATUS}

This project is complete.

\section{DOE FACILITY POINT OF CONTACT}

Shaun Gleason

Martin Marietta Energy Systems

P.O. Box 2009

Oak Ridge, TN 37831-6011

423-574-8259

\section{PARTNER POINT OF CONTACT}

Ashok Kulkarni

KLA Instruments Corporation

P.O. Box 49055

San Jose, CA 95161-9055

\section{PROJECT EXAMPLES}

No project examples are available due time lapse between the end of the project and the writing of this report.

\section{TECHNOLOGY COMMERCIALIZATIONS}

The path to commercialization of the ADC technology has already been established by KLA. For example, work that MMES performed with regard to the radial basis function network classifier led to the integration of this classification scheme into KLA's existing ADC prototype located at a customer site. The ADC tool provided by MMES will be a valuable research test bed that KLA can use to evaluate the applicability of various combinations of features and classifiers. 


\section{DISTRIBUTION:}

S. S. Gleason, MS-6011, 3546

D. W. McDonald, MS-6005, 3500

K. W. Tobin, MS-6011, 3546

M. A. Hunt, MS-6011, 3546

H. Sari-Sarraf, MS-6011, 3546

Brian B. Bovee, MS-8242, 701SCA

Ray Ford, MS-8084, 9203

Joyce Shepherd, MS-6416, 5002

Andy Stevens, DOE/Or, MS-8009, 9704-2

Diane Bird, DOE DP-17

Bill Wilburn, MS-8015, 9704-2

Lab Records, MS-6285, 4500-N

Y-12 Central Files, MS-8169, 9711-5 (3 copies)

Ashok Kulkarni, KLA Instruments Corporation, P.O. Box 49055, San Jose, CA 95161-9055 (5 copies) 